\title{
A WEB-BASED KNOWLEDGE AIDED TUTORING SYSTEM FOR VEGETABLE SUPPLY CHAIN
}

\author{
Hui $\mathrm{Li}^{1,2}$, Zetian $\mathrm{Fu}^{1,2, *}$, Yan $\mathrm{Li}^{3}$, Jian Zhang ${ }^{1,2}$ \\ ${ }^{1}$ College of Engineering, China Agricultural University, Beijing, China, 100083 \\ ${ }^{2}$ Key Laboratory of Modern Precision Agriculture System Integration, Ministry of Education, \\ Beijing, China, 100083 \\ ${ }^{3}$ China Agricultural University, Beijing, China, 100083 \\ * Corresponding author, Address: P.O. Box 121, China Agricultural University, 17 Tsinghua \\ East Road, Beijing, 100083, P. R. China, Tel: +86-10-62736717, Fax: +86-10-62736717, \\ Email:fzt@cau.edu.cn
}

Abstract: With the recent rapid progress of computer technology, researchers have attempted to adopt artificial intelligence and computer networks to develop computer-aided tutoring systems. Meanwhile, some have also attempted to develop more effective programs to test and enhance the learning performance of students. This study surveyed the current theoretical basis and design principle and proposed a web-based knowledge aided tutoring system for vegetable supply chain. The main idea of this paper was focused on the interactive design and feedback control. The proposed concept was illustrated by the functions of chat system, discussion section, questionnaires and online learning record, etc.

Keywords: Computer aided tutoring, Vegetable supply chain, Interactive design, Feedback control

\section{INTRODUCTION}

With accelerated growth of computer and communication technologies, researchers have attempted to adopt computer network technology for research on education. Notable examples include the development of computer-aided tutoring and testing systems (Hopper, 1992). In 1989, Johnson et al. proposed a software design and development research program called Microcomputer Intelligence for Technical Training (MITT).

Li, H., Fu, Z., Li, Y. and Zhang, J., 2008, in IFIP International Federation for Information Processing, Volume 259; Computer and Computing Technologies in Agriculture, Vol. 2; Daoliang Li; (Boston: Springer), pp. 1029-1036. 
Vasandani et al. developed an intelligent tutoring system that helps to organize system knowledge and operational information to enhance operator performance (Vasandani et al., 1995). Meanwhile, Gonzalez and Ingraham designed an intelligent tutoring system, which was capable of automatically determining exercise progression and remediation during a training session according to past student performance (Gonzalez et al., 1994). Hwang also proposed an intelligent tutoring environment which can detect the on-line behaviors of students (Hwang, 1998). In 2000, Ozdemir and Alpaslan presented an intelligent agent for guiding students through on-line course material. This agent could help students to study course concepts by providing navigational support according to their knowledge level (Ozdemir et al., 2000). Hwang proposed a testing and diagnostic system (Hsu et al., 1997; Hwang, 1999), which involved some sub-tasks, such as the investigation of network-based tutoring systems, network learning environments, knowledge-based systems for tutoring process control and interaction pattern analysis.

Clearly, the development of tutoring systems and learning environments has become an important issue in both computer science and education. The rapid development of computer networks is allowing access to information and communication free of spatial and temporal constraints (Hwang, 2003). Network communications allow problems to be solved through on-line discussion, and thus the implementation of computerized testing and practice systems has become an important issue.

\section{METHODOLOGY}

\subsection{Theoretical Basis}

The web-based computer aided tutoring system is mainly based on psychology and systems science.

The theory of cultural and historical development of psychologist Л.С.Выготский. According to his points, the thinking and intelligence were developed in the activities, subjected to internal digestion of interactions. The learners could turn the ability obtained during cooperative and interactive activities into their independent development gains. He proposed the concept of nearest developing section, which meant the difference between actual level and potential level. Full development depended on abundant social interactions. Achievements made by the tutors' instructions and partner' cooperation were far more than that of independent 
learning. And participation in collaborations and thinking could promote the individuals' cognitive development (Zhai et al., 2005; Cen et al., 2005).

Constructivism learning theory. In this theory, knowledge was obtained by the learners through interactions and cooperation under certain situations, using necessary learning materials by way of meaning constructivism. Situation, cooperation, conversation and meaning construction were the four key factors. Accordingly, the web-based computer aided tutoring system provided an integrated leaning environment, abundant interactive opportunities, covering learners, learning resources, man-machine interaction on the learning platform as well as the interaction between learners themselves. They were involved in the cooperation, conversation and learning through the resource system and network support platform and thus the meaning construction was realized (Zhai et al., 2006; Shao 2004).

Systems science - feedback control theory. The web-based computer aided tutoring system was a complicated dynamic system with multi-layers, various types and factors. Evaluation on its effects was a sophisticated systems engineering. It had the function of information feedback, systematically collecting feedback information, processing them to make judgments on teaching effects, and further regulating the teaching methods and scheduling so as to perform the internet learning activities more effectively. Therefore, the web-based computer aided tutoring was a way of macro control over the network tutoring activity system via information transfer, exchange and feedback. Only the control could guarantee stable development of the system with relative balance. So the designs including online learning record of learners and observation of learning attitude, etc. could be introduced into the web-based computer aided tutoring system, so as to know about the learning status, progression and effects of the learners in the internet learning environment. Accordingly the instructors could further improve the teaching methods and strategies according to the feedback.

\subsection{Design Principle}

In the design of web-based computer aided tutoring system, the following principles and requirements should be satisfied. (1) Centering around the learners. The network tutoring had to submit to and serve the learning activities of learners and promote their learning by enlightening their independent thinking and estimation. (2) The demands of communication between learners should be fully considered so as to make them have consciousness of cooperation and interaction, and encourage them being active in the tutoring activities. (3) The technical advantages should be used 
as much as possible to remedy the deficiency of human resources and realized the optimized integration of both. (4) The interaction should be timely, controllable, deep and wide. (5) The feedback should be emphasized. If without feedback design, the web-based computer aided tutoring system could not be a complete one. A scientific tutoring system pays much attention to not only how the instructors teach, but also how the learners study. If the learners make achievements, they should be given timely praise and if they encounter difficulties, they should be given timely encourage and help. To track the status of learners and know about their learning attitude and tendency are favorable to stimulate their enthusiasm, make the tutors obtain effective feedback information and thus properly regulate the teaching procedure.

\section{CASE STUDY}

The web-based knowledge aided tutoring system research for vegetable supply chain was taken as an example in this paper, which was part of the Network-based China Vegetable Supply Chain Management Technology Promotion Project of European Union. The proposed method was illustrated by the example with the analysis of system characteristics from the interactive design and feedback control as well as the function implement.

\subsection{Interactive Design}

To accord with the features of network teaching, firstly, the design should have excellent interactive ability, in which the learners can do selfadjustment according to the progression and selection of teaching materials and learning approaches. And the teachers can make corresponding feedback on the learners' activities and regulate the teaching strategy. Secondly, the design has excellent cooperative ability. The cooperation is advantageous to cultivate the team work spirits of learners and improve cognitive ability. And the network is an ideal site for cooperative learning, in which there are communication platforms such as forums, chat system, BBS, etc. The predominant characteristic of the network is its convenience of intercommunication, free of spatial and temporal constraints. The web-based knowledge aided tutoring system for vegetable supply chain integrated the two merits and realized the cooperative learning centering on interaction, which reflected the 'individual to individual' interaction in the network tutoring system. Therefore, it could provide learners with tools of cooperative learning and network space. Its functions mainly included: 
The excellent interaction was realized by multi-channels as follows: a) BBS (Bulletin Board System) and online chat system. These functions could lead the learners to open discussion and enlighten them to put forward some questions with emanative thinking, so as to improve their learning and creative ability. b) Interactive reply and query system via E-MAIL. c) Cooperative learning group via forum. Exchange and discussion between learners happened within group. In conclusion, the learners could use these network communication platforms to participate in various conversation, negotiation and discussion and thus cultivate their independent thinking, difference thinking, innovative ability and team work spirits (Fig. 1). By these means, in the web-based knowledge aided tutoring system for vegetable supply chain, information communication was realized between learners and teachers and among learners themselves.

Cooperation. In the cooperative learning, the learners participated by way of groups to achieve mutual goals with certain inspiring system, and cooperated to make the maximum benefits. During this course, interaction was the basic unit of stimulating and producing mutual knowledge and conversation was the basis for cooperation. The web-based knowledge aided tutoring system for vegetable supply chain could set up learning groups by various interactive multi-channels and realize group discussion on the internet without getting together in realities.

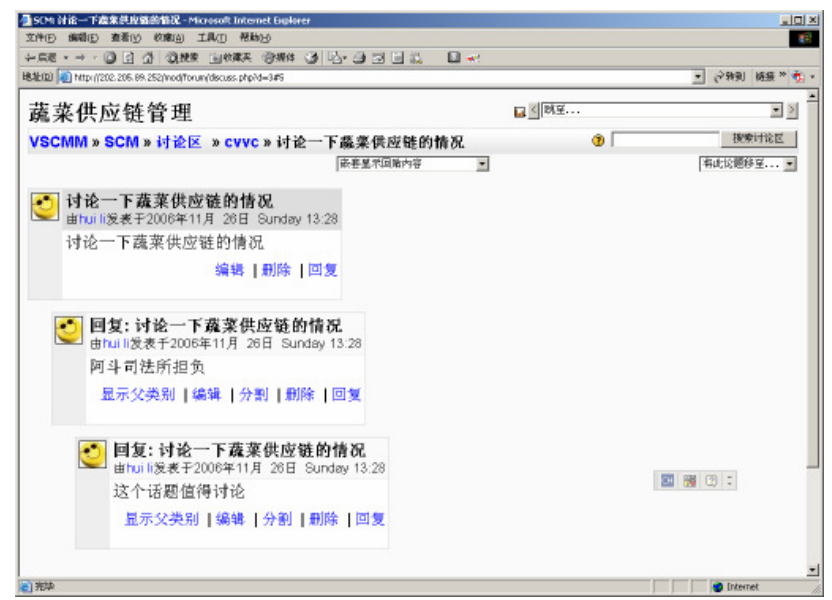

Fig. 1. Asynchronous communication: discussion section

\subsection{Feedback Control}

A good computer aided tutoring system should emphasize the feedback and control in order to guarantee the effective teaching and learning. The learners could do self-adjustment and select teaching materials and learning 
approaches according to their progression. And the teachers could have timely feedback on the learners' activities and attitude and adjust teaching strategy. In the web-based knowledge aided tutoring system for vegetable supply chain, to facilitate the feedback control, the design of learning attitude investigation as well as online learning record were concerned in this study.

Design of learning attitude investigation. The design of the system emphasized on the feedback and control of learning effects, in which the learning attitude investigation of the learners was introduced into the module design. It was an effective and direct way to evaluate on online learning environment based on constructivism theory. The module of questionnaire provided instructions for investigation, which was testified valid in online learning situations. The tutors could make use of these questions to get information from the learners, supervise and find out heir learning attitude and tendency, etc. so as to improve tutoring strategy and accord with the learners' cognitive characteristics and current knowledge background. (Fig. 2)

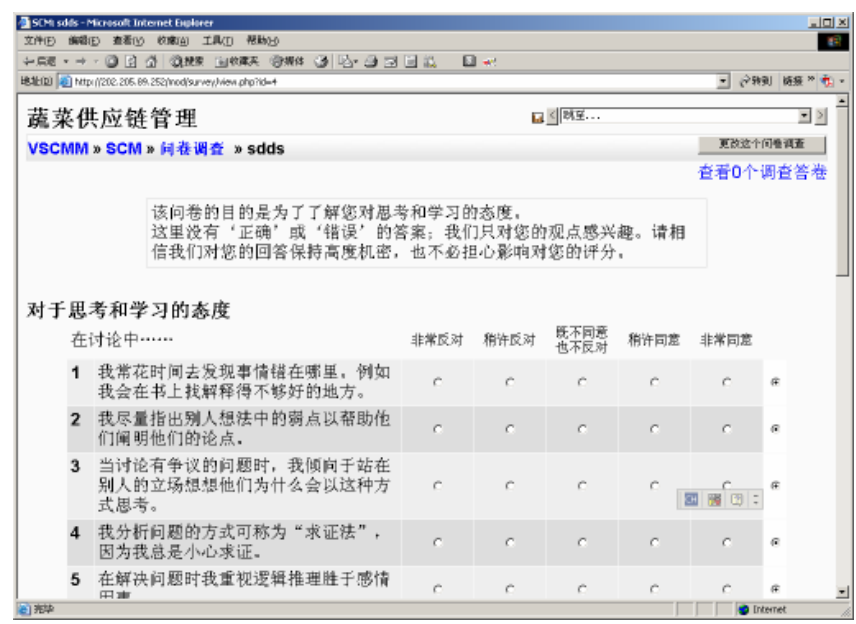

Fig. 2. Design of learning attitude investigation

Online learning record. This function could memorize all the courses the last time the learners entered in, which was useful to understand their various learning status. For instance, it could help to find out the participation enthusiasm and degrees of the learners in the online network learning, and help the learners to get to know the activities and progression of others, so as to inspire them and promote the cooperative atmosphere. It also could let the tutors to know the status, progression and positivity of each learner and accordingly give proper individual instructions and make teaching strategy regulation. This system could fully represent the idea of centering on the learners. (Fig. 3) 


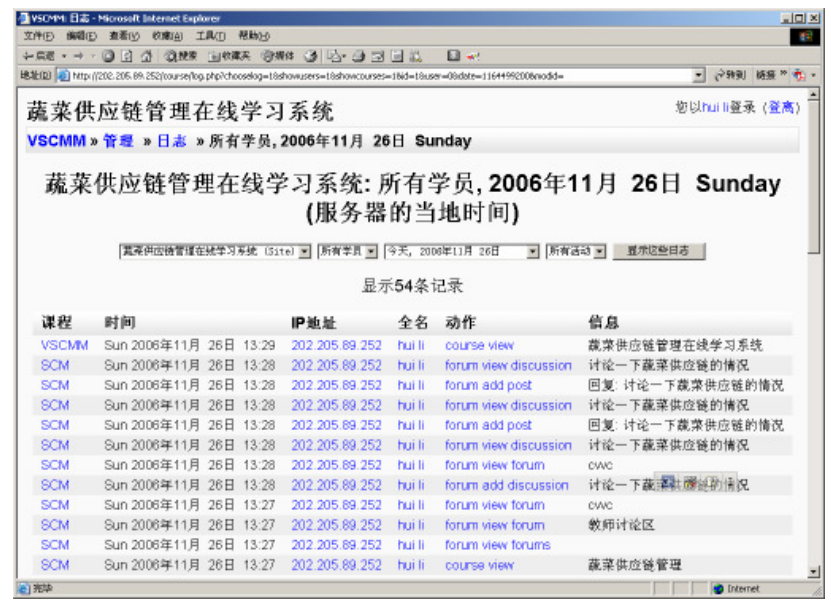

Fig. 3. Online learning record of the learners

\section{CONCLUSIONS AND FUTURE WORKS}

This study proposed a web-based knowledge aided tutoring system for vegetable supply chain. Interaction has been compare to 'conversation' and feedback control compared to 'diagnosis' in the web-based tutoring aided system. Therefore, interactive design and feedback control are of consequence in the system. The usability and practicability of the web-based tutoring aided system have been improved in this study to guarantee the realization of tutoring and learning. Further research will be focused on more effective interaction development.

\section{ACKNOWLEDGEMENTS}

We acknowledge financial support from EU Aided Asia IT \& C (CN/ASIA-IT\&C/005(89099)), and the Ministry of Science \& Technology of China (Integration and application of technology on rural compositive information services).

\section{REFERENCES}

Cen, J. J., Wang, L., Lin, Q. S. Research on Interaction of Online Courseware. Journal of Henan Mechanical and Electrical Engineering College, 2005, 13(5): 113-115.

Gonzalez, A. J., Ingraham, L. R. Automated exercise progression in simulation-based training, IEEE Transactions on Systems, Man and Cybernetics, 1994, 24(6): 863-874. 
Hopper, S. Cooperative learning and computer-based instruction. Educational Technology Research \& Development, 1992, 40(3): 21-38.

Hsu, C. S., Tu, S. F., Yeh, S. Y., et al. Development of an intelligent testing and evaluation system on computer networks. 1997 National Computer Symposium, Taiwan, 1997.

Hwang, G. J. A tutoring strategy supporting system for distance learning on computer networks. IEEE Transactions on Education, 1998, 41(4): 1-19.

Hwang, G. J. Development of an intelligent testing and diagnostic system on computer networks. Proceedings of the National Science Council of ROC, 1999, 9(1): 1-9.

Hwang, G. J. A conceptual map model for developing intelligent tutoring systems. Computers \& Education, 2003, 40: 217-235.

Ozdemir, B., Alpaslan, F. An intelligent tutoring system for student guidance in Web-based courses. Fourth International Conference on Knowledge-Based Intelligent Engineering Systems and Allied Technologies, 2000, 2: 835-839.

Shao, Z. R. The design of net multimedia teaching courseware. Journal of Chongqing Polytechnic College, 2004, 19(6): 40-41.

Vasandani, V., Govindaraj, T. Knowledge organization in intelligent tutoring systems for diagnostic problem solving in complex dynamic domains. IEEE Transactions on Systems, Man and Cybernetics, 1995, 25(7): 1076-1096.

Zhai, R., Feng, S. Z. A study of the model of web-based cooperative learning. Journal of Beijing University of Posts Telecommunications, 2005, 7(1): 39-43.

Zhai, R., Feng, S. Z. A study of interaction design based on the instructional system of multimedia networks. Journal of Beijing University of Posts Telecommunications, 2006, 8(3): 71-75. 